\title{
De Kant a Fichte: apercepção como fundamento*
}

\author{
Thiago S. Santoro*
}

\section{RESUMO:}

O PRESENTE ARTIGO PRETENDE ELUCIDAR O SIGNIFICADO DO PRINCÍPIO DO SISTEMA FILOSÓFICO DE FICHTE, A SABER, A CONSCIÊNCIA-DE-SI DO EU, À LUZ DE SUA HERANÇA KANTIANA. NESSE SENTIDO, A TESE CENTRAL DA DOUTRINA-DACIÊNCIA FICHTIANA SERÁ CONTRAPOSTA ÀS CRITICAS FEITAS POR KANT À POSSIBILIDADE DE UM CONHECIMENTO EFETIVO dO EU, MAIS ESPECIFICAMENTE A PARTIR DE SUA EXPOSIÇÃO DO TEMA NO CAPÍTULO DA PRIMEIRA CRITTICA SOBRE OS PARALOGISMOS DA RAZÃO PURA. O TEXTO SE ENCERRA COM UMA BREVE EXPOSIÇÃO DAS TRANSFORMAÇŌES QUE O CONCEITO DE APERCEPÇÃO RECEBEU NA OBRA DE FICHTE.

PALAVRAS-ChaVE: Kant, Fichte, AutoconsciênCia, Epistemologia

\section{ABSTRACT:}

THE FOLLOWING ARTICLE INTENDS TO CLARIFY THE MEANING OF THE PRINCIPLE OF FICHTE'S PHILOSOPHICAL SYSTEM, THAT IS, THE SELF-CONSCIOUSNESS OF THE I, IN REGARD TO HIS KANTIAN INHERITANCE. IN THIS RESPECT, FICHTE'S CENTRAL THESIS IN THE WISSENSCHAFTSLEHRE WILL BE CONTRASTED to tHE CRITIQUES MADE by KaNT tO THE POSSIBILITY OF AN EFFECTIVE KNOWLEDGE OF THE I, MORE SPECIFICALLY THROUGH HIS EXPOSITION OF THIS SUBJECT IN the Chapter of the first Critique about the paralogisms of pURE REASON. At the end, tHere is a brief PRESENTATION OF THE TRANSFORMATIONS THIS CONCEPT OF APERCEPTION HAS RECEIVED IN FICHTE'S WORK.

KEYWORDS: KANT, FICHTE, SELF-CONSCIOUSNESS, EPISTEMOLOGY

Qual é o sentido fundamental de qualquer filosofia verdadeira? Não será o de tentar libertar a filosofia de qualquer preconceito possível, para fazer dela uma ciência verdadeiramente autônoma, realizada em virtude de evidências últimas, extraídas do próprio sujeito, e encontrando nestas evidências a sua justificação absoluta? Esta exigência, que alguns acham exagerada, não pertencerá à própria essência de qualquer filosofia verdadeira?

\section{Edmund Husserl.}

Certeza é uma palavra filosoficamente perigosa. A exemplo do que diz Santo Agostinho em relação ao tempo, não podemos explicitar adequadamente o que compreendemos interna e obscuramente sobre aquele conceito. Todos o sabem no silêncio do pensar, ninguém no calor do debate. Qualquer discurso a exige como pressuposto tácito que ou-

\footnotetext{
O texto aqui publicado pela primeira vez, com algumas modificações, é parte da dissertação de mestrado defendida pelo autor.

" Doutorando em Filosofia pela Pontifícia Universidade Católica do Rio Grande do Sul.
} 
torga sentido, mas, como na célebre imagem da mão invisível da economia, sua realidade permanece simultaneamente presente e velada, força fundadora e matriz desconhecida do conhecimento. O que significa então perguntar sobre o fundamento último de nosso pensar, esta base inescrutável que sustenta e legitima a própria atividade filosófica? Para obtermos uma resposta adequada, precisamos primeiramente investigar qual o sentido possível da própria pergunta, pois ir ao fundamento, como diz Hegel, pode ser lido também como ir a pique.

O conhecimento sistemático é um fato, e a história do pensamento humano, científico ou filosófico, sua demonstração concreta. A questão em jogo mencionada mais acima não discorre, portanto, sobre o caráter sistemático da razão, e sim procura analisar qual a verdadeira origem do sistema da razão como tal. De acordo com a concepção moderna de racionalidade, pode-se afirmar retroativamente que todo conhecimento pressupõe um sistema, e todo sistema, por sua vez, pressupõe um princípio. Desta afirmação, contudo, muito pouco se pode extrair sobre o conteúdo específico do princípio mesmo. Bem pelo contrário, a noção de princípio fundador do sistema da razão sugere uma total impossibilidade da derivação ao revés, que neste caso seria a tentativa de explicar o princípio a partir do sistema. Neste sentido, o princípio parece estar sempre aquém do próprio sistema. Como diz Fichte em um de seus primeiros escritos, Sobre o Conceito da Doutrina-da-Ciência:

Os princípios de nossos sistemas devem ser - e têm de ser certos antes do sistema. Sua certeza não pode ser demonstrada no âmbito dos sistemas, mas toda prova possível no interior destes já a pressupõe. ${ }^{1}$

O caminho inverso, entretanto, também se mostra como perfeitamente coerente: não podemos pensar sistema e princípio do sistema como entidades isoladas e absolutamente sem relação interna. A verda-

${ }^{1}$ Fichte, J. G. Sämmtliche Werke, vol. I. Berlin: W. de Gruyter, 1971, p. 42. Todos os trechos citados de Fichte têm tradução de Rubens R. Torres Filho, mas indicam a paginação da edição de I. H. Fichte para facilitar a referência. 
de ou certeza do princípio deve ser transmitida e de algum modo estar contida nas partes constituintes do sistema, ou, dito de outro modo, o todo só permanece sistêmico na medida em que segue uma linha mestra de conexão, uma idéia que norteia suas relações internas. Assim, o princípio deixa de ser mera causa independente para afigurar-se como essência imanente que perpassa cada nódulo deste complexo arquitetônico da razão pura.

Todas as regras de inferência da lógica clássica podem servir como belos exemplos desta possível transmissão de verdade entre proposições ou partes de um sistema teórico qualquer. A validade destas regras nos parece inquestionável, e neste parecer está fundada sua rigorosa necessidade. Não sabemos, ou melhor, não podemos pensá-las diferentemente. Ora, eis aqui o verdadeiro ponto cego de toda argumentação sobre a estrutura sistemática da razão. Não há dúvidas de que, após aceitas como verdadeiras tanto premissas quanto regras de transformação, a conseqüente seqüência de proposições deduzidas será também verdadeira. $O$ procedimento é análogo à aceitação das regras de um jogo quando este é corretamente jogado. O problema central não se encontra nestas passagens lógicas de uma determinação à outra do sistema, mas sobretudo na justificação da verdade do próprio princípio, da regra que determina a validade de todas outras regras.

É justamente em torno desta questão aparentemente tão pontual que gira grande parte da obra teórica de Fichte. Os diversos desenvolvimentos da Doutrina-da-Ciência produzidos ao longo da vida do filósofo têm em comum, como um de seus temas principais, a resolução do seguinte problema, já esboçado no Conceito da Doutrina-da-Ciência:

como se funda a certeza do princípio em si; e como se funda a legitimidade de inferir a partir dele, de um determinado modo, a certeza de outras proposições?²

Nesse sentido, Fichte radicaliza a pergunta kantiana sobre as condições a priori de possibilidade de nosso conhecimento do mundo,

\footnotetext{
${ }^{2}$ Idem, p. 43.
} 
pois tenta investigar a origem ou fundamento último que legitima inclusive esta estrutura a priori da razão. ${ }^{3}$

Esta busca incessante pelo princípio pré-lógico, e talvez prédiscursivo, de nossa forma de conhecer a realidade - encontre-se tal forma em sua manifestação empírica ou inteligível - permite a Fichte introduzir uma distinção forte entre a lógica formal clássica e uma possível lógica transcendental. Só assim podemos compreender o tom muitas vezes impositivo com que soam certas afirmações pouco ortodoxas do texto fichteano, como na seguinte passagem:

Daqui se segue a relação determinada da lógica com a Doutrinada-Ciência. A primeira não funda esta última, mas é esta que funda a primeira: a Doutrina-da-Ciência não pode de nenhum modo ser provada a partir da lógica, e não pode pressupor como válida nenhuma proposição lógica, nem mesmo o princípio de contradição; em contrapartida, cada proposição lógica, e a lógica inteira, tem de ser provada a partir da Doutrina-da-Ciência. ${ }^{4}$

O trabalho de investigação proposto pela Doutrina-da-Ciência é, portanto, não mais uma mera elucidação situada do uso adequado que fazemos de nosso aparato conceitual a priori, de nossas formas intrínsecas de relação com o mundo cognoscível, e sim uma verdadeira "escavação" epistemológica rumo ao "subsolo" desconhecido de nosso saber, isto é, uma investigação que parte da certeza de nossos procedimentos mentais em direção ao fundamento desta mesma certeza ou, para usar a expressão do próprio Fichte, “(...) uma dedução genética daquilo que aparece em nossa consciência (...)". ${ }^{5}$ Assim, o filósofo transcendental deve fazer uma suspensão do juízo inclusive sobre a legitimidade das regras lógicas que todo juízo parece inevitavelmente pressupor.

\footnotetext{
${ }^{3}$ Como diz Rubens R. Torres Filho: "Ir além de Kant na direção do fundamento e, com essa marcha regressiva, tomar pé em uma camada transcendental mais profunda: essa é, propriamente, a ambição que inspira a especulação fichteana e Ihe dá, também, seu caráter mais polêmico." In: Torres Fo., R. R. O Espírito e a Letra. São Paulo: Ática, 1975, p. 90.

${ }^{5}$ Fichte, J. G. Sämmtliche Werke, vol. I, p. 68.

${ }^{6}$ Idem, p. 32
} 
Tal como na moral provisória cartesiana, devemos sim manter em uso o meio discursivo do pensar para possibilitar a construção do sistema de todo o saber, mas apenas como construção provisória: precisamos partir de uma proposição qualquer dada, ou de um sistema de proposições, para então investigarmos sua origem última e, conseqüentemente, seu fundamento vivo. A expressão objetiva da Doutrina-da-Ciência construída tem por função tão somente revelar na forma lingüística possível o conteúdo intuitivo primário do conhecimento, isto é, reverter para a letra o significado inerente ao espírito, e destarte tentar minimizar a defasagem entre a certeza imediata do princípio e a necessária mediação de sua exposição. Simples recurso pedagógico, esta constructio ad hoc desempenha o mesmo papel daquela mera escada de que não se cuida mais depois de ter subido. ${ }^{6}$ Mas o que constitui propriamente este conteúdo intuitivo primário do conhecimento? Uma breve remissão a Kant faz-se necessária para reconstruir o percurso traçado pelo projeto filosófico de Fichte.

$\mathrm{Na}$ assim denominada Dedução Transcendental da Crítica da Razão Pura, Kant apresenta o que considera ser o vértice nevrálgico ${ }^{7}$ de sua arquitetônica da razão pura, o eixo sustentador de todo o corpo categorial de nosso entendimento: refiro-me à unidade da apercepção transcendental, termo técnico que designa a necessária referência de todo o variegado da experiência, coligido nas categorias sintéticas do entendimento, ao sujeito desta mesma experiência. Kant procura diferenciar dois modos de acepção desta unidade subjetiva, a saber, relativos ao eu empírico e ao eu puro ou transcendental. Que os sujeitos transcendental e empírico sejam dois aspectos de um mesmo sujeito da experiência e, conseqüentemente, também do próprio pensamento, não poderia, sob pena de comprometer toda e qualquer intenção de sentido do que é dito ou pensado, ser posto em dúvida. ${ }^{8}$ Entretanto, as diversas

\footnotetext{
${ }^{6}$ Cf. Doutrina-da-Ciência de 1804. In: Fichte, J. G. Sämmtliche Werke, vol. X, p. 291. Fichte antecipa aqui, claro que em contexto muito distinto, a famosa metáfora de Wittgenstein no final do Tractatus Logico-Philosophicus.

${ }^{7}$ Mais precisamente nos parágrafos 17 e 18 (B 136 - B 140). Cf. Kant, I. Crítica da Razão Pura. Lisboa: Calouste Gulbenkian, 1997, p. 135-9.

${ }^{8}$ É o que nota David Carr, com razão, sobre o texto kantiano em questão. Cf. Carr, D. The Paradox of Subjectivity: the self in the transcendental tradition. New York: Oxford University Press, 1999, p. 44.
} 
determinações que podemos intuir internamente a respeito do eu empírico estão muito longe de caracterizar minimamente o objeto denominado eu transcendental. Empiricamente, temos uma certeza da determinação do eu em detrimento de sua incondicionalidade. Analiticamente, temos uma certeza desta incondicionalidade em detrimento da determinação do próprio eu. Aqui o dualismo crítico kantiano enfrenta uma difícil separação dos aspectos lógico e empírico da ipseidade, visto que a unidade do sujeito pensante deve estar também, de alguma forma, condicionada à unidade do sujeito concreto.

Esta mesma discussão, na Dialética Transcendental, toma a forma de um paralogismo que, segundo Kant, deve-se justamente à possível confusão entre tais aspectos distintos da subjetividade. Assim, tal paralogismo é considerado mero produto ilusório do ideal da razão. Trata-se aqui da impossibilidade, dentro dos limites determinados da experiência humana finita, de conhecer o sujeito que subjaz e perfaz toda experiência possível. Em outras palavras, o problema em questão consiste na contraposição entre a necessidade lógica de remissão de todas as categorias do pensamento ao eu que pensa e a impossibilidade lógica (ou empírica, ainda não o sabemos ao certo) de tematizar este eu pensante como objeto a ser conhecido pela própria razão. O esforço de esclarecimento crítico sobre o alcance permitido ao entendimento, tarefa modesta de determinar apenas a estrutura interna e objetivamente válida, e não a própria causa da faculdade de pensar ${ }^{9}$, mostra-se incompatível com a pretensa transparência absoluta da razão para consigo ${ }^{10}$. A questão é, a bem dizer, muito mais aguda: para além de todos estes conflitos terminológicos, o que nos interessa saber é sobretudo qual a natureza deste ponto de aglutinação do eu, ponto convergente do pensamento puro com seu ser pensante, corporal e sensível. Como é possível, então, este divórcio irreconciliável na experiência do eu, ora sinônimo de um eu concreto no mundo dos fenômenos, ora antônimo de qualquer concretude no "paraíso lógico" das idéias transcendentais? Vejamos como Kant responde a esta pergunta.

${ }^{9}$ Cf. Kant, I. Op. cit., p. 8 (A XVII).

10 "Nada nos pode aqui escapar, pois o que a razão extrai inteiramente de si mesma não pode estar-Ihe oculto". Idem, p. 10 (A XX). 
Para compreendermos o problema central apresentado nos $\mathrm{Pa}$ ralogismos da Razão Pura, precisamos primeiramente esclarecer alguns pressupostos indispensáveis à argumentação kantiana, pressupostos estes presentes em todo o desenvolvimento da primeira Crítica. Refirome aqui mais especificamente à diferença entre fenômeno e coisa-emsi, bem como à diferenciação que Kant demarca entre as faculdades do entendimento e da razão. Somente a partir destes pares conceituais fundamentais é possível determinar o verdadeiro sentido da discussão sobre o conhecimento de si. Eis uma possível definição da diferença entre entendimento e razão, que, nas palavras de Kant, em B 35911, toma a seguinte forma:
Se o entendimento pode ser definido como a faculdade de unifi- car os fenômenos mediante regras, a razão é a faculdade de unificar as regras do entendimento mediante princípios. Nunca se dirige, portanto, imediatamente à experiência, nem a nenhum objeto, mas tão-só ao entendimento, para conferir ao diverso dos conhecimentos desta faculdade uma unidade a priori, graças a conceitos; unidade que pode chamar-se unidade de razão e é de espécie totalmente diferente da que pode ser realizada pelo entendimento. ${ }^{12}$

Neste princípio hierárquico que escalona as faculdades da razão de acordo com o grau de universalidade da síntese efetuada pelas mesmas, posicionando a razão como meta-faculdade de unificação das categorias do entendimento, já se apresenta delineada uma diferença qualitativa entre as respectivas unidades, grifado no trecho supracitado, fator decisivo na posterior diferenciação entre as unidades empírica e transcendental do eu. Em outras palavras, a unidade efetuada sobre o múltiplo da sensibilidade através das categorias do entendimento precisa agora ser superada através de uma síntese maior, e, assim, a razão deve postular como complemento regulador destas categorias uma idéia

\footnotetext{
${ }^{11}$ A edição portuguesa citada traz, ao invés, A 359, que se confunde com o correto, da página 339 .

${ }^{12}$ Idem, p. 300 (grifo meu). Como regra geral nas citações, será meu todo grifo em negrito.
} 
de unidade total, de síntese absoluta. Mas é justamente esta "espécie totalmente diferente" de unidade visada pela razão que gera o problema epistemológico: ela exige uma unificação de elementos diametralmente opostos, uma síntese do diverso condicionado no incondicionado, isto é, por assim dizer, uma verdadeira união do finito com o infinito. Sobre este ponto, leia-se a seguinte passagem em B 379:

\begin{abstract}
Assim, o conceito transcendental da razão é apenas o conceito da totalidade das condições relativamente a um condicionado dado. Como, porém, só o incondicionado possibilita a totalidade das condições e, reciprocamente, a totalidade das condições é sempre em si mesma incondicionada, um conceito puro da razão pode ser definido, em geral, como o conceito do incondicionado, na medida em que contém um fundamento da síntese do condicionado. ${ }^{13}$
\end{abstract}

Finalmente podemos vislumbrar um primeiro matiz do problema apresentado. Seguindo este preceito do ideal da razão, relativo à base incondicionada como fundamento lógico de toda síntese das condições, o mesmo processo deve ser válido para o conjunto de condições que caracterizam o próprio eu. Tal como na série causal de explicação dos eventos do mundo natural, cuja fundamentação última exige sempre um elemento não causado, isto é, incondicionado, uma tentativa de explicar a unidade do sujeito da experiência requer também, em contraposição ao múltiplo da experiência sensível interna, um elemento unitário incondicionado, um "ponto de fuga" para o qual todos estes variantes internos convergem.

Esta tensão existente entre o múltiplo condicionado do conhecimento ligado à experiência sensível e sua contraparte ideal ditada pela necessidade de síntese absoluta da razão é precisamente o marco divisório que interliga eu empírico e eu transcendental. Não que exista uma divisão real inerente ao próprio sujeito, uma duplicidade do próprio eu que pensa. Muito pelo contrário, como já foi afirmado mais acima, Kant pressupõe como eixo central de toda estrutura sistemática da razão o

\footnotetext{
${ }^{13}$ Idem, p. 314.
} 
que ele denominou unidade sintética da apercepção (ou da autoconsciência $\left.{ }^{14}\right)$ transcendental, cuja caracterização exclui tal possibilidade ${ }^{15}$. O sentido da referida duplicidade de aspectos do eu é, de acordo com a filosofia kantiana, o de distinguir, por um lado, a função sintética do múltiplo fenomênico do sentido interno e, por outro, a função meramente lógica de remissão das categorias do entendimento ao sujeito abstrato do pensamento. Eu empírico e eu transcendental apresentam-se aqui, respectivamente, como conteúdo e forma de um conhecimento possível da subjetividade, fenômeno e coisa-em-si de uma realidade integral do sujeito.

Eis, portanto, o problema indicado: nossa busca de um conhecimento completo e bem fundamentado sobre o próprio eu, seguindo o procedimento que Kant sugere para um correto uso do entendimento, ou seja, obedecendo aos limites impostos pela crítica da razão, deve sempre partir do dado sensível acolhido na forma da sensibilidade (neste caso do sentido interno) e só então progredir a uma síntese cada vez mais ampla ${ }^{16}$ realizada através de noções ou conceitos puros que, por definição, ultrapassam toda a experiência possível..$^{17} \mathrm{O}$ erro, portanto, consiste na confusão de ambos os níveis do discurso, tomando como possível de ser dado na experiência aquilo que a ultrapassa de antemão. Busca-se no entremeado de fenômenos que caracterizam o eu empírico uma representação determinada do eu transcendental, um objeto definido deste eu incondicionado e puro.

Este erro tem a forma de um paralogismo, isto é, de um raciocínio vicioso fundamentado na própria natureza da razão humana, cuja ilusão é inevitável mas não insolúvel. Mais ainda, esta 'ilusão inevitável', que será também inerente às antinomias da razão pura, mostra neste caso paradigmático um sintoma do dualismo apriorístico kantiano: a confusão entre eu empírico e transcendental não se dá por um descuido silogístico ou por qualquer deslize ilusório da percepção, mas sim porque tal confusão é inerente à própria natureza da razão. $\mathrm{O}$ abismo gerado pela neces-

\footnotetext{
${ }^{14}$ Cf. idem, p.132.

${ }^{15}$ Cf., p. ex., idem, p. 333 (B 407).

${ }^{16}$ Cf. idem, p. 314-5 (B 380).

17 Idem, p. 313 (B 377).
} 
sidade de um fundamento incondicionado de todo conhecimento, quanto à representação do eu para si próprio, faz deste mesmo fundamento imagem nula, mero limite visado que nunca pode mostrar-se objetivamente. Por isso escreve Kant, em B 404, sobre este sujeito pensante:

Não podemos dar-Ihe outro fundamento que não seja a representação eu, representação simples e, por si só, totalmente vazia de conteúdo, da qual nem sequer se pode dizer que seja um conceito e que é apenas uma mera consciência que acompanha todos os conceitos. Por este "eu" ou "ele", ou "aquilo" (a coisa) que pensa, nada mais se representa além de um sujeito transcendental dos pensamentos $=\mathrm{X}$, que apenas se conhece pelos pensamentos, que são seus predicados e do qual não podemos ter, isoladamente, o menor conceito; ${ }^{18}$

A diferenciação entre os aspectos empírico e transcendental do eu fica agora evidente: o primeiro consta do conteúdo diverso dos pensamentos que caracterizam a atividade do sujeito pensante, o segundo representa simplesmente, como diz o próprio Kant, "uma mera consciência que acompanha todos os conceitos". O eu transcendental, portanto, de acordo com nosso autor, não pode se tornar objeto de conhecimento determinado, justamente porque exerce uma função limite, determinante da própria possibilidade de qualquer determinação do pensamento. Este sujeito abstrato que pensa, caracterizado de forma meramente negativa, pode apenas tomar consciência de si indiretamente, partindo dos pensamentos determinados que lhe pertencem para, através desta pertença, inferir uma necessária unidade subjacente a todos eles. Assim, podemos postular a unidade da apercepção transcendental como pressuposto inquestionável de toda atividade racional, pressuposto que, aos olhos de Kant, é nada mais do que uma função lógica inscrita na própria constituição de nossa intelecção, cuja verdadeira natureza nos é totalmente oculta. ${ }^{19}$ Assim diz Kant, em B 407:

\footnotetext{
${ }^{18}$ Idem, p. 330.

${ }^{19}$ A 382: "Este eu é tampouco intuição como conceito de qualquer objeto, mas apenas a simples forma da consciência." (Idem, p. 359).
} 
(...) não me conheço unicamente pelo fato de tomar consciência de mim como ser pensante, mas se tiver consciência da intuição de mim próprio como de uma intuição determinada em relação à função do pensamento. Todos os modos da autoconsciência no pensamento não são pois ainda, em si mesmos, conceitos do entendimento relativos a objetos (categorias), mas simples funções lógicas que não dão a conhecer ao pensamento qualquer objeto, nem por conseguinte me dão a conhecer a mim próprio enquanto objeto. ${ }^{20}$

Nesta breve abordagem do Paralogismo Transcendental, vimos como a possibilidade de conhecimento do eu, na sua forma ideal pura, como fundamento incondicional de todo conteúdo diverso da consciência pensante, é, de fato, como acredita Kant, uma simples ilusão da razão. O motivo desta ilusão reside na má compreensão do caráter estritamente regulador que toda idéia transcendental possui perante as categorias finitas do entendimento. Tais idéias - ao contrário dos conceitos, que se referem sempre a algo presente na experiência - não podem denotar nenhuma espécie de conteúdo concreto, nenhum objeto determinado. Por isso Kant adverte mais de uma vez em sua obra ${ }^{21}$ que "a exposição lógica do pensamento em geral é erroneamente considerada uma determinação metafísica do objeto". ${ }^{22}$ Confundimos assim, como deixa muito claro o texto da Crítica, o objeto de conhecimento com sua possibilidade de conhecimento. Em outras palavras, só podemos conhecer o eu fenomênico, que se apresenta para nós na sua condicionalidade temporal e variante. O eu transcendental, esta consciência-de-si que, como coisa-em-si, acaba sempre transformada sob a forma lógica do pensar na consciência-de-um-outro, de um objeto específico presente ao seu "olhar invisível", é a legítima incógnita pré-lógica que sustenta o edifício da razão.

Eis o ponto de apoio que impulsionará o prosseguimento, efetuado por Fichte, do projeto crítico transcendental. O visado princípio fun-

\footnotetext{
${ }^{20}$ Idem, p. 332-3.

${ }^{21}$ Ver também a nota de rodapé em B 624: Idem, p. 503.

22 Idem, p. 340
} 
damental da Doutrina-da-Ciência, e, conseqüentemente, de todo o conhecimento humano, deve agora se tornar explícito e determinado como tal. Este eixo central de nosso saber sistemático, denominado por Kant 'unidade da apercepção transcendental', terá sua função reavaliada na obra fichteana. Mais do que simplesmente uma mera mudança terminológica - pois Fichte descarta o termo técnico kantiano para adotar noções mais coloquiais como 'eu' ou 'autoconsciência' -, o propósito desta reavaliação reside, sobretudo, na tentativa de unificar razão prática e razão teórica. O empenho em estabelecer a autoconsciência como fundamento do conhecimento é também um empenho em estabelecer o primado da práxis no próprio processo cognitivo. Neste sentido, o que antes era visto como função lógico-reguladora dentro do esquematismo da razão pura teórica será agora ponto de unificação entre sujeito do juízo e sujeito judicante. Em outras palavras, Fichte pretende expandir o significado kantiano do sujeito transcendental da experiência, transformando sua unidade potencial em ato puro e presente, sua mera condição de possibilidade da experiência em "experiência" da condição de possibilidade.

Esta aproximação de Fichte à filosofia kantiana é, destarte, também um grande distanciamento. Tal como Kant, Fichte pretende estabelecer os critérios apodíticos de todo conhecimento, evidenciando os pressupostos necessários envolvidos na categorização a priori da realidade fenomênica. Sua mathesis universalis ${ }^{23}$ não deixa de ser uma bela tradução para o esquematismo transcendental normativo da razão pura descrito por Kant. Neste sentido metodológico, ambos permanecem muito próximos, pois procuram determinar as condições de possibilidade da experiência a partir das regras necessárias que as categorias do entendimento ditam à constituição da razão pura como tal. Fichte herdou inegavelmente, através de Kant, esta influência da escola racionalista, que vê no mundo um verdadeiro dualismo epistêmico entre os aspectos empírico e lógico da realidade.

${ }^{23}$ Fichte utiliza o termo máthesis (ou também máthesis da máthesis) para designar a similaridade intuitiva e apodítica entre o procedimento matemático e aquele adotado na Doutrina-da-Ciência. Cf. O Programa da Doutrina-da-Ciência. In: Fichte, J. G. Escritos Filosóficos. Trad. de Rubens R. Torres Filho. In: Coleção Os Pensadores. São Paulo: Abril Cultural, 1973 
Por outro lado, a interpretação que Fichte dá à conexão estrita entre razão prática e razão teórica, fazendo assim da Doutrina-da-Ciência um acabamento do sistema crítico integral almejado por Kant, delimita o ponto de corte entre ambas escolas. Aqui Fichte extrapola as exigências impostas pelo bom uso do entendimento e busca encontrar no primado da razão prática o fundamento último de todo conhecimento teórico. $O$ percurso de investigação da estrutura racional dentro de seus limites objetivos dá lugar a uma investigação dinâmica do próprio processo de reflexão sobre a referida estrutura.

Assim a ciência que acabamos de descrever: Ela é, como tal, não algo que existisse independentemente de nós e sem nossa intervenção, mas, pelo contrário, algo que só pode ser produzido pela liberdade de nosso espírito atuando segundo uma direção determinada. ${ }^{24}$

Fichte precisa agora substituir o eixo de rotação do giro copernicano transcendental: mais do que uma redução do mundo-em-si ao fenômeno intra-subjetivo, a reflexão filosófica deve interiorizar esta bi-partição, de modo a encontrar, no próprio sujeito da experiência, a origem mesma do dualismo crítico.

Mas esta origem monádica que se bifurca em sujeito e objeto do conhecer, agente e mundo de ação, eu e não-eu postulados como partes complementares de um todo maior, deve ser vista como construção ativa. Como diz Fichte, de modo categórico, "teu pensar é para ti um agir."25 A fonte da relação cognitiva é, ela mesma, um ato, e um ato puro de autoposição dos termos relacionados. Neste sentido, o processo de conhecimento é reflexo de um processo anterior de autodeterminação livre do eu; qualquer saber só se torna saber através de um saber-de-si, e este último confundese com a própria essência da ipseidade. Por isso, afirma nosso autor:

O pôr do eu por si mesmo é a sua atividade pura. - O eu põe a si

\footnotetext{
${ }^{24}$ Fichte, J. G. Sämmtliche Werke, vol. I, p. 46.

${ }^{25}$ Fichte, J. G. Sämmtliche Werke, vol. II, p. 522.
} 
mesmo e é, em virtude desse mero pôr-se por si mesmo; e viceversa: o eu é e, em virtude de seu mero ser, põe seu ser. Ele é ao mesmo tempo o agente e o produto da ação; o ativo e aquilo que é produzido pela atividade; ação e feito são um e o mesmo; ${ }^{26}$

Mais do que uma identidade entre produto e produtor, este pôr-asi-mesmo do eu é, além de atividade pura, também uma certeza imediata da consciência-de-si. Pôr-se como eu e saber-se como eu são dois modos de focar o mesmo ponto, duas representações da mesma presença fundamental. Pois a mesma liberdade de autodeterminação intrínseca à natureza do eu é também sua liberdade de intuição imaginadora. Falar sobre um conhecimento imediato do modo-de-ação originário do eu é remeter nossa apreensão conceitual à sua matriz geradora, isto é, investigar sobre a certeza do saber é sobretudo reconhecer na forma do conceito o conteúdo intuitivo que ele representa. É o que nos adverte a seguinte passagem do texto fichteano:

Desde que se começou a falar de uma crítica da razão, de um conhecimento da razão, como conhecida, e tornou-se tarefa da razão conhecer em primeiro lugar a si mesma, e somente a partir disso deduzir como pode conhecer algo fora de si mesma, deveria ter-se tornado claro que essa razão, para apreender-se e captar-se, não poderia fazê-lo em algo derivado, que não tem seu fundamento em si mesmo, como o conceito, mas teria de fazê-lo no único imediato, na intuição; que, portanto, se de agora em diante só se deve chamar de filosofia o conhecimento da própria razão por si mesma, a filosofia não pode absolutamente ser um conhecimento por conceitos, mas tem de ser um conhecimento por intuição. ${ }^{27}$

Logo, certeza e expressão desta mesma certeza devem compor uma e a mesma intuição, coadunando razão fundadora e fenômeno fun-

${ }^{26}$ Fichte, J. G. Sämmtliche Werke, vol. I, p. 96

${ }^{27}$ Fichte, J. G. Escritos Filosóficos, p. 191. 
dado, essência e aparência transcendentais. O que autoriza Fichte, contudo, a ultrapassar o escopo bem delimitado da expressão lingüística do pensamento para supor subjacente a este nível de discurso um elemento pré-discursivo que o fundamenta, uma "entrelinha" cuja correta interpretação mostra sua verdade em "estado bruto"? Como contornar o problema da clausura epistemológica ditada pelo advento do linguistic turn contemporâneo, neste pretenso processo de desvelamento do eu transcendental que põe a si mesmo como fundamento do mundo inteligível? Como, em suma, tematizar racionalmente o que aparentemente constitui o limite indizível da racionalidade, esta autoconsciência pura e livre, geratriz da própria atividade racional?

Qualquer resposta a estas questões deve sempre se prevenir sobre sua modesta insuficiência, deve aceitar a complexa rede de mediações que ela própria acarreta, como percurso inerente ao outro lado do limite. Dizer o indizível, formulação cujo caráter contraditório salta aos olhos, é na verdade um processo positivo de redução ao absurdo, um andar ao avesso que parte do dito em direção ao silenciado, "(...) pois esse silêncio ao qual o discurso quer sacrificar-se só tem sentido através do discurso". ${ }^{28}$ Eis o método regressivo por excelência: sua constante determinação do não-pensamento (por referência negativa) acolhe na forma do pensar o próprio sujeito pensante; aponta com seus conceitos rijos e explícitos para o centro vivo e movente de sua significação. Por isso, diz Fichte na seguinte passagem:

Aquilo que a Doutrina-da-Ciência estabelece é uma proposição pensada e posta em palavras; aquilo que, no espírito humano, corresponde a essa proposição é uma ação qualquer dele, que em si não teria necessariamente de ser pensada. Para esta ação não se pode pressupor nada a não ser aquilo sem o qual ela seria impossível como ação; e isto não é pressuposto tacitamente, mas é ocupação da Doutrina-da-Ciência estabelecê-lo clara e determinadamente, e como aquilo sem o qual a ação seria impossível. ${ }^{29}$

\footnotetext{
${ }^{28}$ Torres Fo., R. R. Op. cit., p. 140.

${ }^{29}$ Fichte, J. G. Sämmtliche Werke, vol. I, p. 79.
} 
Vemos assim que a Doutrina-da-Ciência fichteana oscila constantemente entre dois pólos de construção teórica, criando uma contínua tensão interna de difícil resolução: 1) a tentativa de deduzir as condições a priori de toda experiência cognitiva possível, para, a partir disto, mostrar o corpo teórico sistemático que o princípio visado necessariamente engendra; 2) a tentativa de encontrar uma base pré-reflexiva subjacente ao próprio mapeamento intelectivo fundamental da racionalidade.

No primeiro caso, o modelo de investigação adotado por Fichte espelhando o criticismo dogmático kantiano ${ }^{30}$ - está em pleno acordo com sua própria tradição hermenêutica, ao menos do ponto de vista formal, pois a prova da legitimidade do princípio e de suas conseqüências lógicas é, ela mesma, um esclarecimento lógico desta relação entre princípio fundador e mundo fundado. A busca pelo fundamento último do conhecimento permanece, neste sentido, circunscrita aos limites conceituais ditados pelas regras lógicas, isto é, toda e qualquer explicação do princípio, para tornar-se compreensível, deve tomar como premissa hipotética a validade destas regras e, a partir disso, mostrar retroativamente a dedução das mesmas a partir do princípio. O caminho da argumentação segue, portanto, um círculo, cujo início liga-se a seu próprio fim. Como diz o texto do autor:

As leis (as da lógica geral) segundo as quais é pura e simplesmente necessário pensar este estado-de-ação como fundação do saber humano, ou - o que é o mesmo - as regras segundo as quais esta reflexão é instituída, não foram ainda demonstradas como válidas mas pressupostas tacitamente, como conhecidas e estipuladas. Só bem mais abaixo essas leis são derivadas do princípio cujo estabelecimento só é correto sob a condição da correção delas. Isso é um círculo; mas é um círculo inevitável $(\ldots) .^{31}$

O segundo e conflitante aspecto da teoria epistemológica fichtiana,

${ }^{30}$ Cf. Kant. Op. cit., p. 30 (B XXXV-VI).

${ }^{31}$ Fichte, J. G. Sämmtliche Werke, vol. I, p. 92. 
a saber, a busca por uma certeza imediata pré-lógica ${ }^{32}$, calcada na autoconsciência da ipseidade, precursor longínquo de algumas tendências influentes da fenomenologia e do existencialismo contemporâneo ${ }^{33}$, é, filosoficamente, ao mesmo tempo o maior mérito e a maior dificuldade da Doutrina-da-Ciência. Neste caso, já não lidamos com a organização interconceitual que sustenta o sistema da razão, fechando seu inevitável círculo de determinações recíprocas, mas estamos agora perguntando sobre o elemento constante que permite esta posterior organização lógica interna; estamos à procura do princípio único, esta proposição ou factum fundamental que pode garantir a certeza e o engendramento do todo sistemático.

\begin{abstract}
Esse princípio - da Doutrina-da-Ciência e, por seu intermédio, de todas as ciências e de todo saber - não é, pois, suscetível de absolutamente nenhuma prova, isto é, não pode ser remetido a nenhuma proposição superior da qual, em sua relação com esse princípio, decorresse a sua certeza. Contudo, deve fornecer a fundação de toda certeza; deve, pois, apesar disso, ser certo, e aliás ser certo em si mesmo, em função de si mesmo, e por si mesmo. ${ }^{34}$
\end{abstract}

Para justificar o modo de acesso a esta certeza primeira, Fichte transitará de uma abordagem estritamente proposicional (apresentada como argumento transcendental ${ }^{35}$ na Doutrina-da-Ciência de 1974, primeira edição completa do tratado, única publicada em vida) para uma reconstrução do mesmo argumento em versão mais próxima ao método

\footnotetext{
${ }^{32}$ Cf. Torres Fo. Op. cit., p. 29: "Esse ultrapassamento do conceito, introduzido por uma pergunta pela origem e possibilidade de toda conceitualização, é um dos aspectos pelos quais Fichte se inscreve na linhagem da filosofia transcendental inaugurada por Kant, infletindo-a, entretanto, no sentido de uma de suas conseqüências mais surpreendentes: a necessidade de uma fundação extralógica e pré-lógica da lógica ou, ainda, a admissão de uma anterioridade da reflexão ao pensamento objetivo."

${ }^{33}$ Por exemplo, na tese defendida por Sartre na obra intitulada La Transcendence de l'Ego. Há uma indicação explícita desta similaridade no texto de Neuhouser, F. Fichte's Theory of Subjectivity. Cambridge: Cambridge University Press, 1990, p. 72.

${ }^{34}$ Fichte, J. G. Sämmtliche Werke, vol. I, p. 48.

${ }^{35} \mathrm{Cf}$. Zöller, G. Fichte's Transcendental Philosophy. The Original Duplicity of Intelligence and Will. Cambridge: Cambridge University Press, 1998, p. 32
} 
fenomenológico ${ }^{36}$ (exposta em 1796/99 como Nova Methodo, cujo manuscrito original, perdido, foi reconstruído a partir de anotações de dois dos seus alunos) ${ }^{37}$ até assumir definitivamente o ponto de vista de um saber enquanto imagem do absoluto (presente nas diversas exposições do período pós-Jena). ${ }^{38}$

Como então conciliar duas maneiras aparentemente contraditórias de fundamentar nosso conhecimento, uma que procede através de mediações necessárias que configuram o sistema da razão, outra que procura estabelecer um início imediato cuja certeza deve então validar toda e qualquer construção racional subseqüente? Como unificar imediatez e mediação em uma síntese suprema, de tal sorte que o resultado desta unificação esteja imune aos ataques céticos sobre a possibilidade de uma fundamentação do conhecimento? Em suma, como podemos compreender corretamente a relação intrincada entre pensamento e autoconsciência, bem como seu papel na determinação desta certeza cognitiva?

Seguem algumas indicações para uma possível caracterização desta diferenciação crucial. Em primeiro lugar, no tocante à capacidade de autoconsciência, "a autopercepção requerida para esta consciência não pode ser por sua vez representacional (i.e., marcada por uma distinção entre sujeito e objeto da percepção)". ${ }^{39} \mathrm{O}$ eu, enquanto puramente autoconsciente, deve ter acesso imediato a si mesmo, deve ser e saber de si em um único e mesmo ato. Mas este saber de si não pode ser confundido com o saber reflexivo mediado pelo pensamento. Por isso Fichte muitas vezes denomina tal faculdade pelo termo intuição, como o indica a seguinte passagem:

a autoconsciência é imediata; nela subjetivo e objetivo estão

\footnotetext{
${ }^{36}$ Idem, p. 33.

${ }^{37}$ A tradução inglesa de Daniel Breazeale coligiu em um mesmo texto os dois manuscritos de alunos do próprio Fichte em Jena, documentos conhecidos como Krause e o anônimo Halle Kollegnachschriften.

${ }^{38}$ Ver, por exemplo, a mudança drástica já ocorrida na exposição de $1801 / 2$, traduzida parcialmente sob o título de A Doutrina-da-Ciência e o Saber Absoluto. In: Fichte, J. G. Escritos Filosóficos, p. 253. Ver também Henrich, D. Selbstverhältnisse. Gedanken und Auslegungen zu den Grundlagen der klassischen deutschen Philosophie. Stuttgart: Reclam, 1982, p.79.

${ }^{39}$ Neuhouser, F. Op. cit., p. 75
} 
inseparavelmente unificados e são absolutamente um. (...) Uma

tal consciência imediata chama-se, na expressão científica, uma

intuição, e assim também a chamaremos..$^{40}$

Neste sentido, pensamento e autoconsciência, se me permitem o risco da tese, encontram-se respectivamente como parte e todo do sistema de nossa cognição. O pensamento, enquanto consciência reflexiva, transforma todo saber de si em saber de um outro, pois opera segundo a lei de determinação por oposição. Seu sujeito é sempre, em última instância, um mero objeto. A autoconsciência, em contrapartida, por ser uma capacidade imediata de apreensão, consegue abarcar a totalidade do espaço lógico dentro de si "em um único olhar", determinando com isto a linha limite do campo de nossas representações. $O$ sujeito, neste caso, deve ver a si mesmo enquanto aquele que vê, e jamais enquanto objeto visado. Assim, pensamento e autoconsciência devem ser absolutamente distintos, ou ao menos distintos com relação à sua estrutura cognitiva fundamental. Um não pode ser reduzido ao outro, e toda tentativa de realizar tal redução acarreta plena distorção no significado de ambos os conceitos. Como reafirma Fichte em um texto tardio de 1813:

\begin{abstract}
A Doutrina-da-Ciência é, portanto, aquele saber que pura e simplesmente não pode ser por sua vez objeto de um novo saber, mas é cabalmente apenas consciência. Concebendo e fundando todo o saber restante, ela teria, nisso, de conceber e fundar ao mesmo tempo a si mesma. Se quisermos designar isto nos termos correntes de subjetivo e objetivo: a Doutrina-da-Ciência permanece em toda a eternidade apenas subjetiva e nunca se torna objetiva. ${ }^{41}$
\end{abstract}

\footnotetext{
40 Fichte, J. G. Sämmtliche Werke, vol. I, p. 528

${ }^{41}$ Fichte, J. G. Sämmtliche Werke, vol. X, p. 5. Traduzido e citado por Rubens Rodrigues Torres Filho em: op. cit., p. 260.
} 


\section{BIBLIOGRAFIA:}

CARR, D. The Paradox of Subjectivity: the self in the transcendental tradition. New York: Oxford University Press, 1999.

DÜSING, K. Strukturmodelle des Selbstbewusstseins. In: Fichte-Studien.

Amsterdam: Rodopi, 1995

FICHTE, J. G. Sämmtliche Werke. Berlin: W. de Gruyter, 1971.

Escritos Filosóficos. Trad. de Rubens R. Torres Filho. In: Coleção Os

Pensadores. São Paulo: Abril Cultural, 1973.

Foundations of Transcendental Philosophy: Wissenschaftslehre nova

Methodo 1796/99. Trad. de Daniel Breazeale. Ithaca: Cornell University, 1992. HENRICH, D. Selbstverhältnisse. Gedanken und Auslegungen zu den

Grundlagen der klassischen deutschen Philosophie. Stuttgart: Reclam, 1982. HUSSERL, E. Meditações Cartesianas: introdução à fenomenologia. Porto: Rés, 1980.

KANT, I. Crítica da Razão Pura. Lisboa: Calouste Gulbenkian, 1997.

NEUHOUSER, F. Fichte's Theory of Subjectivity. Cambridge: Cambridge

University Press, 1990.

SARTRE, J-P. A Transcendência do Ego. Lisboa: Colibri, 1994

TORRES Fo., R. R. O Espírito e a Letra. São Paulo: Ática, 1975.

WITTGENSTEIN, L. Tractatus Logico-Philosophicus. São Paulo: Edusp, 1994.

ZÖLLER, G. Fichte's Transcendental Philosophy. The Original Duplicity of

Intelligence and Will. Cambridge: Cambridge University Press, 1998. 